\title{
The ADR rule-of-thumb as predictor of lodging property values
}

\author{
John B. Corgel \\ Cornell University \\ Jan A. deRoos \\ Cornell University
}

In a positive context, asset valuation models may be judged on the basis of their predictive ability rather than on the number and elegance of the underlying assumptions. The Average Daily Rate (ADR) rule-of-thumb has been used for decades as a quick way of estimating hotel and motel room rates and, more recently, as a simple grossincome multiplier model for predicting values of lodging properties. This study examines how well the ADR ruleof-thumb model predicts property values. The results of our comparative analysis of estimates from the ADR model with those from a hedonic valuation model indicate that the ADR model performs well in the aggregate, but is an inconsistent estimator at various levels of disaggregation, such as when property subsamples were organized by number of rooms, age, occupancy rate and number of restaurants.

Key words: ADR rule-of-thumb valuation models lodging properties

\section{Introduction}

In his classic Essays in Positive Economics, Milton Friedman characterized economics as a positive science consisting of generalization about economic phenomena that may be used for prediction (Friedman, 1935). Theories in 'positive' economics are not judged on the basis of the realism or elegance of their assumptions, but rather, on their ability to predict the outcomes from human interactions. Neoclassical economics has produced an assortment of models for valuing real estate. Some of these models are quite simplistic in their underlying assumptions, while others have many detailed assumptions. The trend in real estate valuation has been toward development and application of models with explicit and detailed sets of assumptions. Less structured models may be useful (in a positive context) for valuation only if empirical tests show that they have predictive power.

Application of simple ratio models based on the relationship between either the development or reproduction cost and average daily room rate (ADR) of hotels and motels has a longstanding tradition in the lodging industry. The development costs of properties have been used as the economic foundation for deriving quick estimates of how much to charge per night for rooms (Vallen and Vallen, 1991; Kasavana and Brooks, 1991). Sometimes observed room rates are used to easily generate estimates of the values of properties. When used for valuation purposes, the relationships take the following forms:

$$
V=\operatorname{ADR}(1000)(R)
$$

and

$$
V / R=\operatorname{ADR}(1000)
$$

where $\mathrm{V}$ is the value of the lodging property, $A D R$ is the average daily rate from lodging property operations, and $\mathrm{R}$ is the number of available rooms.

In this paper, we compare value estimates from the ADR rule-of-thumb model to value estimates from an economic fundamentals model. The economic fundamentals model is a hedonic pricing model that has been customized for lodging property valuation. In the aggregate, the ADR rule-of-thumb model yields estimates of lodging property values that only differ slightly from hedonic estimates. When the property sample is disaggregated, using physical characteristics and financial performance characteristics as the cross- $\neg$ sections, many statistically significant differences in the estimates from the two models are found. These results suggest that care must be taken when interpreting results from aggregate comparative analyses of the hotel and motel values. 
The balance of the paper is organized into three sections. The next section presents the background of rule-ofthumb valuation models and specifically the ADR rule. The section that follows describes the development of the economic fundamentals model and how the comparative analysis was performed. The findings and conclusions from the study are contained in the final section.

\section{Rule-of-thumb models in perspective}

The modern convention in asset valuation is for models to be heavily structured with assumptions and for rigorous statistical estimation of model parameters. Figure 1 traces two historical paths in the development of asset valuation models. The ex-ante models shown along one path are based on the concept that buyers and sellers make decisions from forecasts of future incomes. The simple, rule-of-thumb models found along the early part of this path rely on few assumptions about future incomes. Discounted cash flow and option pricing models attempt to capture the economic fundamentals of decisions through precision in the estimation of future incomes and through explicit recognition of market participant behavior.

Ex-post models, shown along the second path, are conceptually based on the idea that buyers and sellers make decisions from knowledge of recent transactions in the space and asset markets. Rule-of-thumb models of this variety relate prices to the physical characteristics of assets. And as with income-based rule-of-thumb models, much judgment is required to reach value conclusions. By contrast, hedonic models introduce a broader spectrum of physical and other asset characteristics and bring greater objectivity to transaction-based valuation.

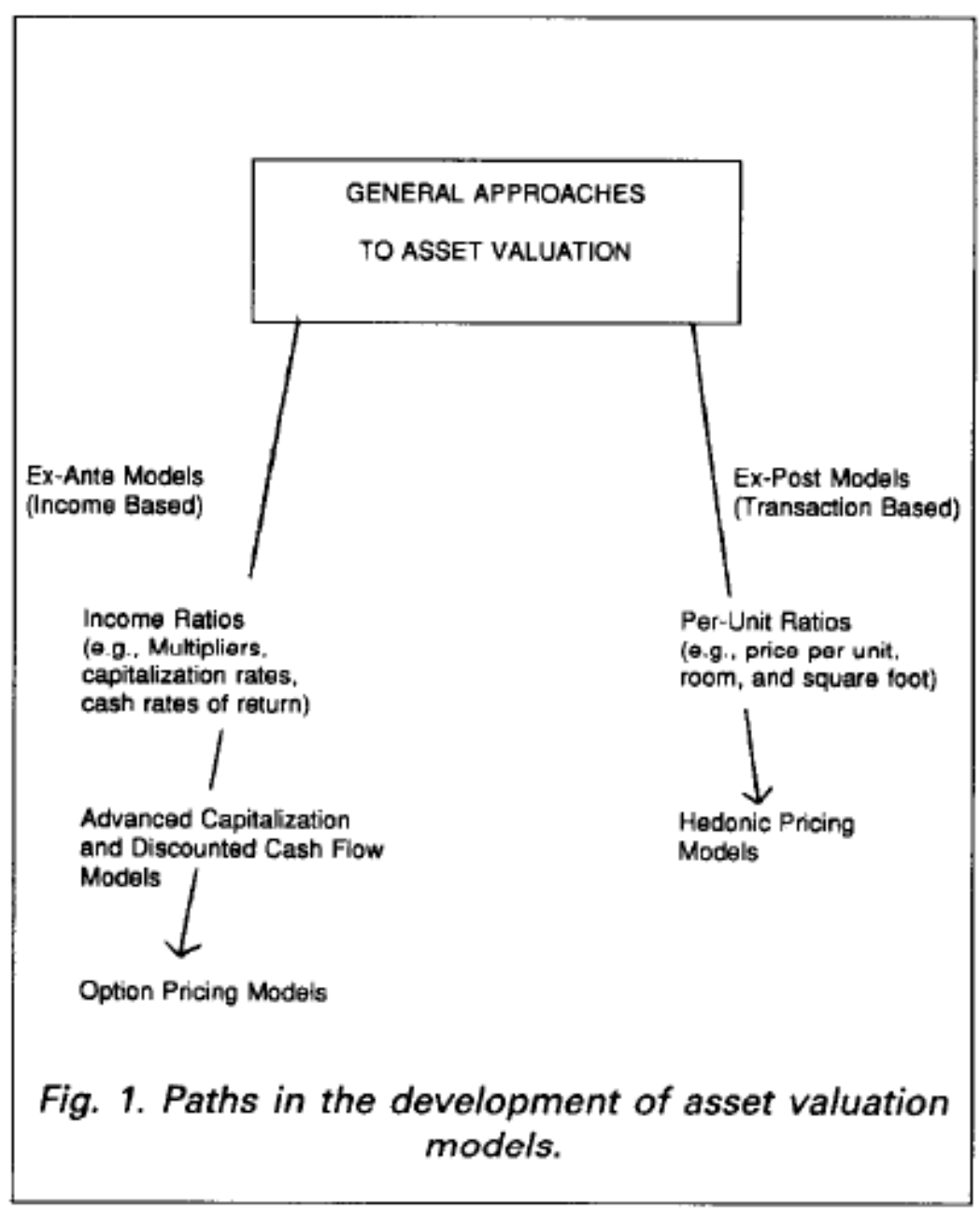




\section{Previous literature}

Advances in modelling asset value may be critically examined by subjecting the models to the rule of parsimony. During the 1950s and 1960s, studies by Gordon (1955) and Sarnat and Levy (1969) concluded that the reciprocal of the payback period, a rule-of-thumb model, and the internal rate of return, a fundamentals model, produce different results that are predictable in a limited set of cases. These studies, which were limited to investments with level incomes and zero residual values, found accounting return to be an inaccurate measure of internal rate of return and the errors between accounting return and internal rate of return are neither constant nor consistent (see Livingston and Solomon, 1970 for a review of the early studies). Recently, Fama and French (1992) presented surprising evidence that simple size ratios and equity ratios explain cross-sectional stock returns better than the Capital Asset Pricing Model.

From the literature comparing real estate valuation models, Smith (1985) describes the limiting conditions under which traditional rule-of-thumb models such as gross-income multipliers, overall capitalization rates, and cash-on-cash measures of real estate return will approximate discounted cash flow (DCF) model results for multi-family properties. ${ }^{*}$ These limiting conditions, however, are sufficiently restrictive to make it improbable that rule-of-thumb and DCF models will yield consistent results. Lusht (1978) found no meaningful relationships between rule-of-thumb models, particularly first-year cash flow and DCF results. Geltner et al. (1991), who compare real estate capitalization rates derived from a simple mortgage-equity formula with those from an economic fundamentals model, also find no relationships. Mitchell and Bernes (1992), however, report strong correlations when comparing value estimates for multi-family properties using income and physical/transactional ratios (e.g. rent per square foot) versus hedonic model estimates.

Intuitively, models that are driven by assumptions closely resembling economic fundamentals for which the parameters are estimated objectively, should produce different estimates than rule-of-thumb models. The literature provides general verification of this notion, yet there may be circumstances under which the differences are either small or predictable.

The literature on lodging property valuation is not highly developed relative to advancements in modelling values of other capital assets. Further, there are no published studies that compare estimates of lodging property values from alternative valuation models. The comparative analysis of a simple rule-of-thumb model and a sophisticated sales comparison model performed in this study thus begins to fill the large void in our understanding of how to value perhaps the most important assets on the balance sheets of lodging and related companies.

\section{The ADR rule-of-thumb}

As in other industries, rules-of-thumb are part of the heritage of the lodging industry. An often expressed industry standard, for example, is that the number of employees needed in a full service lodging operation is equal to the number of available rooms. * Room rates are equated to property development costs and values in similar ways by traditional standard. The rule that $\$ 1$ of ADR equals $\$ 1000$ of development costs is evidenced through examples found in several early hotel management (Podd and Lesure, 1964) and marketing (Coffman, 1970) texts. In their 1991 text, Vallen and Vallen refer to the rule as the 'building cost method' for evaluating room rates. Use of the rule is characterized as analogous to an old cookbook direction-'flavor to taste'. Yet, they note that the rule is still applied directly on the theory that rising construction costs are matched by rising room rates. Advocates of the rule also may argue that it works more effectively for economy hotels. Kasavana and Brooks (1991), in another recent hotel management text, recom - mend that the rule be restructured as a relationship between ADR and the replacement cost of the hotel to adjust for inflation.

\footnotetext{
* Most of the limiting conditions require constant relationship for incomes and expenses across properties and over time. See smith (1985, pp. 548-550)
} 
Rushmore's (1990a, 1990b) writings legitimize the ADR rule-of-thumb as an alternative model for valuing new and existing lodging properties. Yet, he makes it clear that the reliability of the model for general usage is questionable. In Rushmore (1990b), an existing property's value is estimated consistently with the room rate multiplier and six other valuation models. (Room rate multiplier is ADR $\times 1000 \times$ R.) In Rushmore (1990a), the rule is presented along with cautionary notes. Implicit in the rule are assumptions about occupancy, ratio of food and beverage revenue to rooms revenue, and other costs and expenses. The multiplier, therefore, should be adjusted if the subject property's operating characteristics vary from those assumed for direct use of the rule. This model should be used to 'establish broad parameters for room rates and project value' (pp. 11-17).

The advantages of applying the ADR rule-of-thumb model for valuation are clearer than the disadvantages. In exchange for ease and expedition, many assumptions must be made implicitly, and a high degree of subjectivity is introduced to reach value conclusions from the ADR model.

\section{Relationships between ADR rule and capitalization rate}

As with any gross-income multiplier, and ADR multiplier, 1000(R), may be converted to an annual capitalization rate by making some explicit market and property assumptions. Let ARR be annual room revenues so that:

$$
\operatorname{ARR}=\operatorname{ADR} 365(R)
$$

and

$$
\mathrm{ADR}=\mathrm{ARR} / 365(R)
$$

Substituting equation (3) into the ADR rule-of-thumb equation (1a):

$$
V=\operatorname{ADR}(1000)(R)
$$

gives an annual gross income multiplier model:

$$
V=2.7397 \text { (ARR). }
$$

If average annual occupancy is assumed to be $70 \%$, the annual operating expense ratio is $60 \%$ and there is no food and beverage revenue then the net operating income (NOI) multiplier is

$$
\mathrm{V}=9.78 \text { (NOI), }
$$

and the capitalization rate is $10.22 \%$.

\section{Testing and the ADR rule}

To determine whether the ADR rule-of-thumb model is a reliable, as well as quick and easy valuation tool, we compare the value estimates from the ADR model to value estimates from a model based on the fundamental economic characteristics of properties. This section describes the property sales data and how the fundamentals model is developed.

\section{Property sales}

A data base contains over 1,100 lodging property sales occurring from 1985 and 1991. In addition to the observed sale price, over 100 pieces of information are recorded for each sale, including details about the property's 
physical characteristics, ownership form, location, and local market conditions. Table 1 presents selected information available for most transactions (see Corgel and deRoos, 1992) for a more complete description of these data).

Over one-half of the sales in the data base have been omitted from consideration in this

\begin{tabular}{ll} 
Table 1. Selected information on lodging property sales \\
\hline Variable name & \\
\hline$S$ & Selling price adjusted for extraordinary financing and ground leases \\
$R$ & $\begin{array}{l}\text { Either ADR or published single occupancy rate at time of sale (ADR } \\
\text { used in regressions) } \\
\text { Occupancy at time of sale }\end{array}$ \\
OCC & Number of rooms at time of sale \\
$R O O M$ & Age in years at time of sale \\
$A G E$ & Properties with meeting and banquet facilities \\
$M E E T$ & Ownership form of buyers and sellers including individuals, \\
$B U Y, S E L$ & partnerships, domestic real estate corporation, domestic hotel \\
& corporation, foreign corporation, domestic institution, and foreign \\
& institution \\
CHAN & Affiliation with major lodging chain \\
LTD & Limited service lodging facility \\
$D E L X$ & Properties with high levels of amenities \\
$S U I T$ & All suite lodging properties \\
$G O L F$ & Properties with golf as an amenity \\
$T E N$ & Properties with tennis as an amenity \\
$P O O L 1-N$ & Properties with one or more pools \\
$R E S T 1-N$ & Properties with one or more food and beverage operations \\
$A I R$ & Properties within two miles of an airport \\
$T C O M$ & Time in minutes between a property and the nearest commercial center \\
$E M P$ & Number of employed persons in the county during the month of sale \\
$E M P C$ & Change in EMP (annual rate) \\
$E B I$ & Effective buying income per capita in the county during the year of sale \\
$Y 85-Y 91$ & Year of sale
\end{tabular}

study because either the published room rate is available instead of the ADR, occupancy is unavailable, or the property has extraordinary characteristics, such as casino gaming. The final sample of 513 sales has the general statistical profile shown in Table 2. None of these properties was taken out of service following the sale.

Fundamentals model

The common practice in studies of this type is to compare the rule-of-thumb model estimates to those of a fundamentals model. The fundamentals model may be either income-based (Gordon, 1955; Sarnat and Levy, 1969; Lusht, 1978; Geltner etal., 1991) or transaction-based (Mitchell and Bernes, 1992). We use a two-equation, transactionbased model to obtain estimates of the market value of lodging properties. The equations for room rate and for sale price have the following functional forms: 


$$
\begin{gathered}
R_{i}=r\left(O_{i}, M_{i}, P_{i}, L_{i}, E_{i}, T_{i} ; \beta, e\right) \\
S_{i}=s\left(P_{i}, L_{i}, E_{i}, C_{i}, Q_{i}, T_{i} ; \beta^{*}, u\right),
\end{gathered}
$$

where

\begin{tabular}{|lccc}
\hline \multicolumn{4}{l}{ Table 2. Statistical profile of property sales } \\
\hline Variable & $\begin{array}{c}\text { Number of } \\
\text { observations }\end{array}$ & Mean & $\begin{array}{c}\text { Standard } \\
\text { deviation }\end{array}$ \\
\hline $\begin{array}{l}\text { Sale price (adjusted for } \\
\text { financing) }\end{array}$ & 513 & $\$ 9,362,922$ & $\$ 20,700,818$ \\
Average daily rate & 513 & $\$ 49.06$ & $\$ 28.64$ \\
Number of rooms & 513 & 164 & 112 \\
Average occupancy & 513 & $61.39 \%$ & $12.48 \%$ \\
Age & 513 & 14 years & 15 years \\
Number of restaurants & & & \\
Zero & 186 & & \\
One & 249 & & \\
Two & 61 & & \\
Three & 14 & & \\
Four & 3 & & \\
Year of sale & & & \\
1985 & 44 & & \\
1986 & 63 & & \\
1987 & 42 & & \\
1988 & 104 & & \\
1989 & 128 & & \\
1990 & 116 & & \\
1991 & 16 &
\end{tabular}

$R_{i} \quad$ is the room rate of the $i$ th property at time of sale

$S_{i} \quad$ is the cash equivalent sale price of the $i$ th property

$O_{i} \quad$ is the occupancy of the $i$ th property at time of sale

$M_{i} \quad$ is the market segment of the $i$ th property at time of sale

$P_{i} \quad$ is a vector of property characteristics of the $i$ th property at the time of sale

$L_{i} \quad$ is a vector of locational characteristics of the $i$ th property at the time of sale

$E_{i} \quad$ is a vector of economic characteristics of the local area in which the $i$ th property is located at time of sale

$C_{i} \quad$ is a vector of sale contract characteristics of the $i$ th property transaction

$T_{i} \quad$ is the year of sale of the $i$ th property

$Q_{i} \quad$ is an unobserved quality measure of the $i$ th property at the time of sale $\beta, e, \beta^{*}, u$ are estimated parameters of the models and error terms. 
characteristics, local area characteristics, and time (year) dummies on the right side. Then, the residual from this regression $(Q)$ is introduced as an explanatory variable in the sale price equation. The sale price equation has cashequivalent sale price on the left side, and on the right side, the same property, location, and local market variables as the rate equation plus information about the buyers and sellers in the transactions. The buyer and seller categorical variables are entered in the price equation to pick up unique motivational considerations and informational problems associated with the parties in the contracts for sale. For example, certain investor types may have overpaid for properties as the result of tax transfer opportunities (e.g. limited partnerships) and poor market information (e.g. foreign investors). Similarly, the room rate equation contains variables not found in the price equation. Occupancy is included to account for demand and supply interactive effects as are the market segment variables (i.e. suite, limited service, deluxe, and middle market).

Experiments with various functional forms revealed that the semi-log form provided the best fit of the data. The variances of the equations are adjusted using a heterostedasticity consistent covariance matrix following White (1980) and the severity of collinearity among the explanatory variables is low to moderate.

The estimated room rate equation is (t-statistics are calculated using heterostedasticity consistent standard errors):

\begin{tabular}{|c|c|c|c|c|}
\hline$(R)$ & $\begin{aligned}= & 2.7021 \\
& (22.80) \dagger \\
+ & 0.0001 \text { AGE2 } \\
& (0.61) \\
- & 0.1223 \text { CHAN } \\
& (3.57) \dagger \\
+ & 0.0669 \text { POOL2 } \\
& (0.97) \\
+ & 0.2029 \text { REST2 } \\
& (3.28) \dagger \\
- & 0.0019 \text { TCOM } \\
& (1.63) \\
+ & 0.0056 \text { Y86 } \\
& (0.10) \\
+ & 0.0116 \text { Y90 } \\
& (0.23)\end{aligned}$ & $\begin{aligned}+ & 0.0038 \text { OCC } \\
& (3.46) \div \\
+ & 0.3082 \text { DELX } \\
& (6.92) \dagger \\
- & 0.0403 \text { GOLF } \\
& (0.43) \\
- & 0.0670 \text { POOL3 } \\
& (0.22) \\
+ & 0.2995 \text { REST3 } \\
& (2.15)^{*} \\
+ & 0.0001 \text { EMP } \\
& (2.19)^{*} \\
-0.0001 \text { Y } & (07 \\
& (0.16) \\
+ & 0.0225 Y 91 \\
& (0.31)\end{aligned}$ & $\begin{aligned}+ & 0.0006 \text { ROOM } \\
& (2.57) \dagger \\
+ & 0.4058 \text { SUIT } \\
& (6.74) \dagger \\
+ & 0.1224 \text { TEN } \\
& (2.15)^{*} \\
+ & 0.1065 \text { MEET } \\
& (3.35) \dagger \\
+ & 0.3514 \text { REST4 } \\
& (1.51) \\
+ & 0.0003 \text { EMPC } \\
& (0.10) \\
+ & 0.0722 \text { YS8 } \\
& (1.39)\end{aligned}$ & $\begin{aligned}+ & 0.0006 \text { AGE } \\
& (0.24) \\
+ & 0.0335 \text { LTD } \\
& (0.74) \\
+ & 0.0406 \text { POOLI } \\
& (1.08) \\
+ & 0.1080 \text { RESTI } \\
& (2.21)^{*} \\
+ & 0.0069 \text { AIR } \\
& (0.21) \\
+ & 0.0371 \text { EBI } \\
& (7.55)^{\dagger} \\
+ & 0.0618 \mathrm{YS9} \\
& (1.22)\end{aligned}$ \\
\hline
\end{tabular}

${ }^{*}$ Significant at 0.05 level.

$\uparrow$ Significant at 0.01 level.

The estimated sale price equation is ( $t$-statistics are from heterostedasticity consistent standard errors):

$\begin{array}{rlrlr}\text { LOG }(C E P)= & 12.90 & +0.0059 \text { ROOM } & -0.0174 \text { AGE } & +0.0001 \text { AGE2 } \\ & (90.88) \dagger & (18.93) \dagger & (5.04) \dagger & (2.82) \dagger \\ - & 0.2189 \text { GOLF } & +0.0566 \text { TEN } & +1417 \text { POOLI } & +0.1645 \text { POOL2 } \\ & (0.53) & (0.53) & (2.24)^{*} & (1.71) \\ - & 0.2096 \text { POOL3 } & -0.0157 \text { CHAN } & +0.3054 \text { MEET } & +0.0618 \text { RESTI } \\ & (0.69) & (0.28) & (5.87) \dagger & (1.00) \\ + & 0.3268 \text { REST2 } & +0.2842 \text { REST3 } & +0.8427 \text { REST4 } & -0.0568 \text { AIR } \\ & (3.71) \dagger & (1.61) & (4.37) \dagger & (1.04) \\ - & 0.0041 \text { TCOM } & +0.0002 \text { EMP } & +0.0137 \text { EMPC } & +0.0751 \text { EBI } \\ & (2.03)^{*} & (5.15) \dagger & (3.51) \dagger & (10.28) \dagger\end{array}$




$\begin{array}{cccc}+0.2425 \text { BUYP } & +0.1874 \text { BUYDC } & +0.3464 \text { BUYDI } & +0.4429 B U Y F \\ (3.57) \dagger & (3.01) \dagger & (3.38) \dagger & (3.67) \dagger \\ +0.1677 \text { SELP } & +0.1046 \text { SELDC } & -0.2107 \text { SELDI } & -0.0763 \text { SELF } \\ (2.33)^{*} & (1.54) & (2.93) \dagger & (0.36) \\ +0.0178 Q & +0.0446 Y 86 & -0.1617 Y 87 & -0.0928 Y 88 \\ (14.92) \dagger & (0.55) & (1.62) & (3.48) \dagger \\ -0.2930 Y 89 & -0.3277 Y 90 & -0.3653 Y 91 & \\ (3.47) \dagger & (3.67) \dagger & (2.67) \dagger & \\ N=513, R^{2} A D J=0.8466, S E E=0.4593 . & \text { Mean LOG(CEP) }=15.2056 .\end{array}$

${ }^{*}$ Significant at 0.05 level.

†Significant at 0.01 level.

The purpose of estimating these equations is not to test specific hypotheses, but instead to generate estimates of value from a fundamentals model. Yet, some interesting observations about the parameters are offered. First, property characteristics such as the number of rooms, age, pools, meeting rooms, and food and beverage facilities have statistically significant relationships to room rates and sale prices. Second, several of the buyer and seller categorical variables, which attempt to capture the incentives of different types of market participants, are important. Third, the location variables AIR and TCOM are surprisingly unimportant in these equations. Finally, the local and economic variables have a large and statistically significant effect on room rates and sales prices.

\section{Findings from the comparative analysis}

Both the ADR rule-of-thumb model and the fundamentals model yield a value prediction for each property in the sample. The sample means of $\$ 9,705,850$ (rule-of-thumb) and $\$ 9,578,474$ (fundamentals) are only $\$ 127,376$ apart. The rule-of-thumb model overpredicts by a mere $1.3 \%$ and the difference between predictions is not statistically different from zero. In addition, the standard deviation of the rule-of-thumb prediction is one half of the fundamentals model prediction.

When the sample is disaggregated by key property and operating characteristics, the comparative analysis produces results that are quite different from the results using the entire sample. Table 3 presents the mean differences (DIF) between predictions from the rule-of-thumb model and the fundamentals model for selected property and operating characteristics. In addition to mean values and standard errors, the f-tests are reported for various levels of each characteristic. A t-statistic that is significant either at the 0.01 or 0.05 level is indicative that the two models produce significantly different market value predictions. In such cases, the rule-of-thumb equation is not considered to be a reliable valuation model.

\section{Univariate analysis}

The series of univariate t-tests is performed on variables that, in theory, reveal whether the rule-of-thumb model overpredicts or underpredicts lodging property value. Two physical property characteristics are tested; the number of rooms (ROOM) and the age of the property $\{A G E)$. The variable ROOM is divided into four categories ranging from fewer than 75 rooms to over 300 rooms. Because the number of rooms is a scaler in the ADR rule-of-thumb model, the model may become less reliable as the size of the properties increases. As shown in Table 3, the rule-of-thumb model is reliable for properties with $75-149$ rooms, but unreliable for properties in other size categories. 


\begin{tabular}{|c|c|c|c|c|}
\hline Variable & $N$ & $\begin{array}{c}\text { Mean difference } \\
\text { (rule - fundamentals) }\end{array}$ & $\begin{array}{c}\text { Standard } \\
\text { error }\end{array}$ & $t$-statistic \\
\hline Room No. & & $\$$ & $\$$ & \\
\hline$<75$ & 97 & 299,848 & 59,093 & $5.07 \dagger$ \\
\hline 75-149 & 204 & $1,038,467$ & 610,212 & 1.70 \\
\hline $150-299$ & 154 & $3,110,381$ & 540,562 & $5.75 t$ \\
\hline$>300$ & 58 & $-11,285,994$ & $5,601,949$ & $2.01^{*}$ \\
\hline$A G E(Y r)$ & & $\$$ & $\$$ & \\
\hline 1 & 30 & $-8,858,902$ & $8,516,191$ & 1.04 \\
\hline $2-5$ & 142 & 88,272 & 691,985 & 0.027 \\
\hline $6-10$ & 84 & $2,754,674$ & 518,999 & $5.31 t$ \\
\hline $11-20$ & 155 & $1,275,100$ & $1,038,927$ & 1.22 \\
\hline $21-50$ & 83 & $1,758,882$ & 430,509 & $4.08 \dagger$ \\
\hline$>50$ & 19 & $-14,244,435$ & $8,759,776$ & 1.62 \\
\hline$R(\$)$ & & $\$$ & $\$$ & \\
\hline$<30$ & 76 & 682,497 & 85,375 & $7.99+$ \\
\hline$\$ 30-\$ 44.99$ & 215 & $1,512,004$ & 132,691 & $11.39 \dagger$ \\
\hline$\$ 45-\$ 59.99$ & 103 & $2,541,267$ & 259,019 & $9.81 \dagger$ \\
\hline$\$ 60-\$ 84.99$ & 88 & $3,164,223$ & 974,615 & $3.24 t$ \\
\hline$>\$ 85$ & 31 & $-27,477,717$ & $10,415,278$ & $2.63 t$ \\
\hline $\operatorname{OCC}(\%)$ & & $\$$ & $\$$ & \\
\hline$>80$ & 39 & 567,732 & $1,796,079$ & 0.31 \\
\hline 70-79.99 & 101 & $-1,810,239$ & $1,920,571$ & 0.94 \\
\hline $60-69.99$ & 167 & $-668,161$ & $1,642,596$ & 0.40 \\
\hline $50-59.99$ & 130 & $1,363,616$ & 998,750 & 1.36 \\
\hline$<50$ & 76 & $2,109,859$ & 333,249 & $6.33 \dagger$ \\
\hline REST No. & & $\$$ & $\$$ & \\
\hline 0 & 186 & 966,827 & 85,200 & $11.35 t$ \\
\hline 1 & 249 & $1,518,099$ & $1,067,471$ & 1.42 \\
\hline 2 & 61 & $-1,502,168$ & $2,923,501$ & 0.51 \\
\hline 3 & 14 & $-16,385,373$ & $10,028,844$ & 1.63 \\
\hline 4 & 3 & $-57,155,095$ & $9,535,184$ & $5.99+$ \\
\hline MEET & & $\$$ & $\$$ & \\
\hline With & 370 & $-227,561$ & 992,359 & 0.22 \\
\hline Without & 143 & $1,045,746$ & 166,805 & $6.27 \dagger$ \\
\hline$Y$ & & $\$$ & $\$$ & \\
\hline 1985 & 44 & $-99,695$ & $\$ 862,291$ & 0.12 \\
\hline 1986 & 63 & $-5,322,587$ & $2,998,555$ & 1.77 \\
\hline 1987 & 42 & $2,092,092$ & 324,347 & $6.45 t$ \\
\hline 1988 & 104 & 529,693 & 959,240 & 0.55 \\
\hline 1989 & 128 & $1,676,057$ & $1,040,411$ & 1.61 \\
\hline 1990 & 116 & 211,467 & $2,239,504$ & 0.09 \\
\hline 1991 & 16 & $1,439,488$ & $2,684,785$ & 0.53 \\
\hline
\end{tabular}

The rule-of-thumb model traditionally has been used as an aid in decision-making for development of new lodging properties, and to a lesser extent associated with room rates and values of older existing properties. Thus, the ADR model may be more reliable for newer properties than for older properties. The univariate tests, however, suggest no clear relationship between AGE and the reliability of the ADR model.

Because of the implicit assumptions in the ADR model regarding property financial performance (Rushmore, 1990a), the model may predict better at some levels of average room rate (R), occupancy (OCC), restaurant operation 
(REST), and business meeting operations (MEET) than others. As in the case of ROOM, R is a scaler in the ADR rule- ofthumb equation. Thus, the ADR model is expected to be less reliable as $R$ increases. The univariate results in Table 3 suggest that the ADR model is unreliable at all levels of $R$. The model significantly overpredicts value at lower room rates and significantly underpredicts value at room rates greater than $\$ 85$.

Because the ADR model only explicitly recognizes room revenue, the model may not be effective in valuing properties with substantial food and beverage and meeting businesses. The univariate f-tests in Table 3 indicate that not only is the model unreliable for valuing properties with four restaurants, but also is unreliable for valuing properties with no food and beverage business. In addition, the ADR model generates predictions that are consistent with the fundamentals model for properties with meeting space, and predictions that are inconsistent for properties without meeting space. These results are contrary to what is expected.

Finally, the univariate comparative analysis is conducted with the year the property sold as the focus variable. During those years that tax advantages from owning real estate had a large role in market behavior, the ADR rule-ofthumb model should be less reliable than for other years. Again, the reasoning for this position is that tax effects are not explicitly recognized in the ADR model. This hypothesis only is supported by the statistics for 1987.

\section{Multivariate analysis}

In addition to the series of univariate tests, a multivariate test is performed using the same list of variables except $\mathrm{R}$ which is highly collinear with some other variables. The dependent variable in the regression is the absolute value of the difference between predictions using the ADR rule-of-thumb model and the fundamentals model. The estimated regression equation has the form:

$$
\begin{aligned}
& \text { DIF }=-9,806,353 \quad+63,456 \text { ROOM } \quad+67,149 \text { AGE } \quad+18,006 \text { OCC } \\
& (2.33) \dagger \\
& (8.37) \dagger \\
& -1,615,380 \text { REST1 } \quad-2,437,484 \text { REST2 } \\
& \text { (0.98) (0.95) } \\
& +27,030,914 \text { REST4 -1,368,839 MEET } \quad+4,732,668 \text { Y86 } \\
& (3.10) \dagger \\
& (0.86) \\
& \text { (1.66) } \\
& +6,407,300 \text { REST3 } \\
& (0.36) \\
& \text { (1.44) } \\
& \text { (1.78) } \\
& +3,179,710 \text { Y87 } \\
& \text { (1.07) } \\
& +5,508,385 Y 90 \\
& +2,555,362 Y 88 \\
& \text { (1.03) } \\
& +2,041,078 \text { Y91 } \\
& +4,428,419 Y 89 \\
& \text { (1.83) } \\
& (2.23)^{*} \\
& \text { (0.51) } \\
& N=513, R^{2} A D J=0.2469, S E E=13,494,402, \text { Mean } D I F=4,712,109 .
\end{aligned}
$$

*Significant at 0.05 level.

tSignificant at 0.01 level.

A significant coefficient (positive or negative) suggests that the variable is statistically important for explaining the inefficiency of the ADR rule-of-thumb model, holding other factors constant. The significance of the ROOM variable supports the notion that the ADR rule is less efficient for larger properties. Also, the rule tends to become less efficient as the number of restaurants increases. These results are consistent with our expectations.

\section{Conclusions}

Asset valuation experts will select the simple, parsimonious model over the elaborate, assumption-laden model if the two models perform with equal precision. Given the trend toward the development of stylized valuation models, it is important to confirm that explicit statements of implicit relations indeed constitute advancements in valuation methodology. Our examination of the predictive ability of a simple rule-of-thumb model for valuing lodging properties 
shows that the model is unreliable except in cases in which there are high degrees of data aggregation. Generally, we find that the ADR rule-of- thumb model does not generate predictions that are consistent with an economic fundamentals model, and that the predictions it produces are inconsistent across various types of lodging properties.

Although the ADR model is well understood by professionals, easy and inexpensive to use, and has a longstanding tradition, we conclude that it has limited use as a property valuation tool.

Acknowledgements - The authors wish to extend our sincere appreciation to Stephen Rushmore and Daniel Lesser of Hospitality Valuation Services and the many members of the Hotel Motel Brokers Association for their co-operation in assembling the data for this study. This study could not have been completed without the financial support of the Cornell University School of Hotel Administration.

\section{References}

Coffman, C. D. (1970) Marketing for a Full House. Cornell University, Ithaca, New York.

Corgel, J. B. and deRoos, J. A. (1992) Pure price changes of lodging properties. Cornell Hotel and Restaurant Administration Quarterly 33 April, 2-9.

Fama, E. F. and French, K. R. (1992) The cross-section of expected stock returns. Journal of Finance 47 June, 427-465. Friedman, M. (1935) Essays in Positive Economics. University of Chicago Press, Chicago.

Geltner, D., McConaughy, D. and Miller, N. (1991) Cap rates: appraisers' rule-of-thumb versus DCF fundamentals. Working paper, Department of Finance, University of Cincinnati.

Gordon, M. J. (1955) The payoff period and the rate of profit. Journal of Business 28, 253-260.

Kasavana, M. L. and Brooks, R. M. (1991) Managing Front Office Operations. Educational Institute, American Hotel and Motel Association, East Lansing, Michigan.

Livingston, J. L. and Solomon, G. L. (1970) Relationships between accounting and internal rate of return measures: a synthesis and analysis. Journal of Accounting Research 8 Autumn, 199-216.

Lusht, K. M. (1978) Measuring rate of return: two rules-of-thumb v. the internal rate. Appraisal Journal 45, 245-256.

Mitchell, P. S. and Bernes, G. L. (1992) Validation of basic valuation models: a multifamily housing example. Real Estate Issues 17 Spring/Summer, 8-12.

Podd, G. O. and Lesure, J. D. (1964) Planning and Operating Motels and Motor Hotels. Ahrens, New York.

Rushmore, S. (1990a) Hotel Investments: A Guide for Lenders and Owners, pp. 11-16, 11-17. Warren Gorham and Lamont, Boston.

Rushmore, S. (1990b) Hotel valuation techniques. Real Estate Finance Journal 6 Summer, 50-57.

Sarnat, M. and Levy, H. (1969) The relationship of rules of thumb to the internal rate of return: a restatement and generalization. Journal of Finance 24 June, 479-490.

Smith, L. B. (1985) Rental apartment valuation: the applicability of rules of thumb. Appraisal Journal 52 October, 541552.

Vallen, J. J. and Vallen, G. K. (1991) Check-In Check-Out. William C. Brown, Dubuque, lowa.

White, H. (1980) A heteroskedasticity-consistent covariance matrix estimator and a direct test for heteroskedasticity. Econometrics 48 (4), 817-838. 
* Most of the limiting conditions require constant relationship for incomes and expenses across properties and over time. See Smith (1985, pp. 548-550). 